\title{
Eficiência operacional na colheita mecanizada em lavouras de arroz irrigado
}

\author{
Operational efficiency in mechanized harvesting in irrigated rice fields
}

\author{
Pietro Furian Araldi ${ }^{*}$ José Fernando Schlosser ${ }^{I}$ Ulisses Giacomini Frantz \\ Rodrigo Lampert Ribas ${ }^{I}$ Paula Machado dos Santos ${ }^{\text {II }}$
}

\section{RESUMO}

\begin{abstract}
O objetivo deste trabalho foi avaliar a eficiência de campo e de tempo na operação de colheita mecanizada em lavouras de arroz irrigado, localizadas na região da Depressão Central do Rio Grande do Sul. Na safra 2008/2009, foram avaliadas propriedades que utilizaram lavouras sistematizadas com nivelamento da superfície do solo em nível e com nivelamento da superfície do solo em desnível. Durante as operações, foram coletados os dados para o cálculo das eficiências de campo $e$ de tempo, através de caderneta de campo, cronômetro, e com auxílio de um aparelho receptor de sinal de GPS (Global Positioning System). Não houve diferença significativa, em nivel de $5 \%$ de probabilidade de erro, entre as duas modalidades de sistematização para as eficiências estudadas. Para eficiência de campo, encontrou-se um valor médio de $65,2 \%$ e, para a eficiência de tempo, 75,7\%. O tempo de descarga foi o fator que teve maior correlação negativa com a eficiência de tempo, e os fatores tempo de deslocamento e deslocamento médio foram os que tiveram maior correlação negativa com a eficiência de campo. Realizar as descargas com a colhedora em operação e evitar efetuar manobras nos vértices das lavouras, quando possivel, mesmo que se perca em eficiência da barra de corte, podem otimizar a eficiência de campo.
\end{abstract}

Palavras-chave: desempenho de colhedoras autopropelidas, lavoura orizícola, sistematização.

\section{ABSTRACT}

The objective of this research was to evaluate the time efficiency and the field efficiency of the harvesting operation in rice fields, located in the region of Depressão Central of Rio Grande do Sul, Brazil. In the summer of 2008/2009, 19 operations were evaluated, being fifteen fields of them with land level and four without land level. The operation data were collected through the use of stopwatch, a clip board to record observations and with a signal receiver of GPS (Global Positioning System). There was no significant difference in the 5\% level of probability of error between operations with land level and operations without land level. The field efficiency was calculated through the methodology used by GRISSO et al. (2002), and have been found the average of $65.2 \%$, the time efficiency was determinate based on the concept of Hunt (2001), which have determined an average of $75.7 \%$. Unload making combining with operation increase the field efficiency.

Key words: time efficiency, field efficiency, land level.

\section{INTRODUÇÃO}

Os custos com as operações mecanizadas em lavouras de arroz irrigado no Rio Grande do Sul (RS) representam uma grande parcela nos custos totais de produção, sendo que, na safra 2009/2010, os gastos chegaram a aproximadamente $30 \%$ destes. Entre as operações mecanizadas, destacase a colheita, que, nesta mesma safra, representou $10,46 \%$ do custo total de produção (IRGA, 2010).

Eficiência de campo é um importante critério para verificar a capacidade de campo e para tomar importantes decisões sobre o gerenciamento das máquinas (GRISSO et al., 2002). Segundo a norma ASAE D497.6 (2009), eficiência de campo é a relação entre a capacidade de campo efetiva de uma máquina pela sua capacidade de campo teórica. Esta eficiência está relacionada com o não aproveitamento da largura total de trabalho da máquina, com os hábitos do operador, tempo de manobras e características da área. De acordo com HUNT (2001), eficiência de tempo é o resultado da

'Departamento de Engenharia Rural (DER), Universidade Federal de Santa Maria (UFSM), Avenida Roraima, 1000, 97105-900, Santa Maria, RS, Brasil. E-mail: pietroaraldi@gmail.com*Autor para correspondência.

"Instituto Federal de Educação Ciência e Tecnologia Farroupilha, Campus Alegrete, Alegrete, RS, Brasil. 
relação entre o tempo que a máquina efetivamente trabalhou na operação de campo e o tempo que ela utilizou para realizar a operação.

Os dados georreferenciados, coletados através de um receptor GPS (Global Positioning System), podem auxiliar na operação e no gerenciamento de máquinas agrícolas. Os dados adquiridos durante a colheita fornecem informações relativas às características operacionais da colhedora automotriz, como velocidade, percursos realizados, tempo de descarga e capacidade de campo (GRISSO et al., 2002).

Informações sobre a operação de colheita podem indicar ações capazes de reduzir o seu custo e consequentemente aumentar a rentabilidade das lavouras de arroz irrigado. O correto planejamento, mais especificamente por meio de um adequado dimensionamento da colhedora evita sua subutilização. Porém, para efetuar esse dimensionamento de forma adequada, é necessário conhecer informações sobre as eficiências dessa operação, segundo as condições em que as colhedoras irão operar.

Devido à importância técnica e econômica do uso de colhedoras outopropelidas em lavouras de arroz irrigado, este trabalho teve como objetivo geral avaliar a eficiência operacional na colheita mecanizada em lavouras de arroz irrigado na região da Depressão Central (DC) do RS. Mais especificamente, buscouse determinar e avaliar a eficiência de campo (e\%) e de tempo $(\mathrm{Et} \%)$, verificar se existe diferença entre as duas modalidades de sistematização do solo para as variáveis estudadas, comparar a eficiência de campo média encontrada com a eficiência de campo estabelecida pela ASAE D497.6 (2009), determinar qual o tempo utilizado em manobras e descargas, e elencar as variáveis que possuem maior correlação com a redução das eficiências.

\section{MATERIAL E MÉTODOS}

Os dados foram coletados em seis propriedades que adotam o sistema de cultivo de arroz irrigado na região da Depressão Central do $\mathrm{RS}$, denominadas como propriedades A, B, C, D, E e F (para evitar a identificação dos proprietários), em lavouras com sistematização com nivelamento da superfície do solo em nível (SN) e lavouras com sistematização com nivelamento da superfície do solo em desnível (SD). A tabela 1 mostra as características das propriedades e colhedoras avaliadas.

Os dados para a determinação dos parâmetros operacionais foram coletados na safra 2008/2009, entre o período dos meses de fevereiro a abril de 2009 (Tabela 1). Esses dados foram coletados através de um receptor de sinal GPS (Global Positioning System), marca Garmin modelo 60CSX, método utilizado por PERIN (2008), e através de caderneta de campo, prancheta e cronômetro.

Com o receptor de sinal GPS de navegação, seguiu-se a seguinte sistemática: em primeiro lugar, a área a ser colhida foi medida com o receptor de sinal GPS, a seguir, o aparelho foi fixado na colhedora automotriz para a coleta dos dados de velocidade instantânea, coordenadas (longitude e latitude), data, hora e distância percorrida.

$\mathrm{Na}$ coleta de dados com caderneta de campo, prancheta e cronômetro, a pessoa designada para essa tarefa acompanhou a colhedora automotriz do início ao fim da operação, anotando os dados necessários para os cálculos dos parâmetros

Tabela 1 - Divisão das propriedades conforme a modalidade de sistematização, número de lavouras e características das colhedoras utilizadas.

\begin{tabular}{|c|c|c|c|c|c|c|c|}
\hline \multirow[b]{2}{*}{ Sistematização } & \multirow[b]{2}{*}{$\begin{array}{l}\text { Município da } \\
\text { propriedade }\end{array}$} & \multirow[b]{2}{*}{ Gleba } & \multirow{2}{*}{$\begin{array}{c}\mathrm{N}^{9} \mathrm{de} \\
\text { lavouras }\end{array}$} & \multirow[b]{2}{*}{ Área (ha) } & \multicolumn{3}{|c|}{--Características das colhedoras autopropelidas utilizadas-- } \\
\hline & & & & & Marca/modelo & $\begin{array}{l}\text { Rodado/sistema } \\
\text { separação }\end{array}$ & $\begin{array}{l}\text { Largura barra } \\
\text { de corte }(\mathrm{m})\end{array}$ \\
\hline \multirow[t]{5}{*}{$\mathrm{SN}$} & São Sepé & A & 2 & 1,$92 ; 0,96$ & SLC 6200 & Esteira/Saca-palhas & 3,96 \\
\hline & Santa Maria & $\mathrm{B}$ & 2 & 3,$25 ; 0,69$ & $\mathrm{SLC} / 6200$ & Pneu/Saca-palhas & 3,96 \\
\hline & Silveira Martins & $\mathrm{C}$ & 2 & $(0,69 ; 0,39 ; 0,24 ; 0,18)$ & $\mathrm{MF} / 5650$ & Pneu/Saca-palhas & 3,96 \\
\hline & Arroio Grande & $\mathrm{D}$ & 3 & $(1,11 ; 1,24 ; 0,97)$ & $\mathrm{MF} / 3640$ & Pneu/Saca-palhas & 3,96 \\
\hline & Cachoeira do Sul & $\mathrm{E}$ & 4 & $(3,3 ; 0,98 ; 1,04 ; 7,73)$ & $\mathrm{JD} / 1450$ & Esteira/Saca-palhas & 5,79 \\
\hline \multirow[t]{3}{*}{ SD } & São Sepé & A & 1 & 17,02 & $\mathrm{SLC} / 6200$ & Esteira/Saca-palhas & 3,96 \\
\hline & Arroio Grande & $\mathrm{D}$ & 2 & 0,$95 ; 2,25$ & $\mathrm{MF} / 3640$ & Pneu/Saca-palhas & 3,96 \\
\hline & Cachoeira do Sul & $\mathrm{F}$ & 1 & 5,24 & $\mathrm{MF} / 3640$ & Pneu/Saca-palhas & 3,96 \\
\hline
\end{tabular}

MF (Massey Ferguson), JD (John Deere) 
operacionais. Foram coletados dados referentes à propriedade, colhedora e operação (data, hora do início, hora do fim, tempo total da operação, tempo das manobras (TM\%), tempo das descargas (TDC\%), tempo dos deslocamentos (TDL\%, gasto em deslocamentos dentro da lavoura quando a colhedora automotriz não estava efetivamente colhendo - idas até a carreta graneleira para descarregar o arroz colhido, saída da lavoura, desatolamentos), tempo necessário para resolução de imprevistos, reparos e/ ou embuchamentos (TP\%), número de manobras, número de descargas, número de deslocamentos e número de embuchamentos).

Após, os dados coletados foram analisados com o auxílio dos seguintes softwares: GPS TrackMaker $^{\circledR}$, Versão Professional 4.7, Microsoft Office Excel $^{\circledR} 2007$ e software científico SISVAR, versão 5.3 (FERREIRA, 2008).

De posse dos dados adquiridos nas propriedades, calcularam-se as variáveis relacionadas com a operação (deslocamento médio da colhedora, tempos gastos durante a operação e relação comprimento/largura da gleba) e as eficiências da operação (eficiência de campo, conforme norma ASAE D496.2 (2003) e eficiência de tempo, conforme HUNT (2001) (Figura 1).

Sabendo-se que os fatores tempo de manobras, tempo de descargas, tempo de deslocamento e velocidade de deslocamento interferem na eficiência de colheita (WITNEY, 1988; HUNT, 2001; TAYLOR et al., 2001), calculou-se o coeficiente de correlação de Pearson $(\rho)$ entre as variáveis (Tabela 2 ).

$\mathrm{O}$ teste $\mathrm{F}$ foi aplicado para determinar se houve diferença significativa entre as duas modalidades de sistematização para as seguintes variáveis: e\%; Et\%; TM\%; TDL\%; TDC\%. Utilizouse o delineamento experimental de blocos ao acaso, em que as modalidades de sistematização do solo foram consideradas os tratamentos e as propriedades os blocos, por se tratarem de propriedades com características ambientais, possivelmente heterogêneas, o que totalizou dois tratamentos, sendo as lavouras com $\mathrm{SN}$ o tratamento $\mathrm{N}$, e as lavouras com SD o tratamento $\mathrm{D}$. Na busca por uma aleatoriedade na amostragem de propriedades que caracterizassem lavouras na Depressão Central do RS, elas não apresentavam características idênticas, não sendo possível coletar dados quanto aos dois tipos de sistematizações nas propriedades B, C, E e $\mathrm{F}$, pois possuíam glebas com apenas uma modalidade de sistematização, necessitando ser realizada uma análise de blocos incompletos. Foram realizadas 5 repetições para o tratamento $\mathrm{N}$ e 3 repetições para o tratamento $\mathrm{D}$, e utilizou-se um nível de significância de $5 \%$ de probablilidade de erro.

\section{RESULTADOS E DISCUSSÃO}

Para as duas eficiências determinadas (e\% e Et\%) e as variáveis correlacionadas (TM\%; TDL\%; TDC\%), não houve diferença significativa entre as lavouras SN e SD. Assim, as avaliações levaram em consideração os valores gerais encontrados nas lavouras.

\section{Eficiência de Tempo (Et\%)}

A média geral do tempo total não aproveitável (TNA\%) foi de 24,30\%, ou seja, do tempo total utilizado pelas colhedoras automotrizes para efetuar a operação, 24,30\% foram consumidos em manobras, descargas, deslocamentos e/ou resolução de imprevistos (Tabela 2). Os valores médios para Et\%, TM\%, TDC\%, TDL\% e TP\% foram, respectivamente: $75,70 \%, 11,10 \%, 10,78 \%$, $1,77 \%$ e $0,65 \%$ (Tabela 2 ).

Os valores de Et\% variaram de 57,4 a $87,6 \%$. A tabela 2 mostra que a causa dessa variação está relacionada com os tempos não aproveitáveis. A menor Et\% apresentou um TNA\% de 42,6\%, aproximadamente $75 \%$ maior que a média, o que é causa direta do TDC\% dessa operação, pois essa variável possui o maior valor entre as operações avaliadas. Já o maior valor de Et\% deve-se principalmente aos dois fatores de maior influência no TNA\%, TM\% e TDC\%, pois tem valores inferiores as suas médias, com destaque para o TM\%.

Podemos observar, na tabela 2 , que houve grande variação nos fatores manobras e descargas, o primeiro fator variou de 2,26 a $25,02 \%$, com média $11,08 \%$, e o segundo variou de 0 a $29,26 \%$, com média $10,76 \%$. Nas manobras, os dois valores mais altos, 23,08 e 25,02\%, ocorreram em duas operações na propriedade $\mathrm{C}$, isto se deve o fato de as descargas terem sido feitas com a colhedora em movimento. Os valores mais baixos $(2,26 \%, 2,44 \%$ e 3,44\%) são de lavouras com SN da propriedade E. Eles são explicados pela sua alta relação comprimento/largura (F/W), o que diminui o número de manobras por área colhida (Tabela 2).

A eficiência de tempo obteve correlação mais alta com a variável tempo de descarga, com valores de $-0,6$, para todas as lavouras, e $-0,8$, excluindo-se as duas lavouras da propriedade $\mathrm{C}$ que não tiverem tempo de descarga (Tabela 2). Essa correlação negativa indica que, com o aumento dos tempos de descarga, a eficiência de tempo foi reduzida.

TAYLOR et al. (2002), avaliando a eficiência da colheita mecanizada de soja e milho, encontrou um tempo médio não aproveitável de $44,64 \%$, contra os $24,30 \%$ encontrados no presente trabalho. Essa superioridade é devida principalmente a três fatores: primeiro, os tempos problemas 


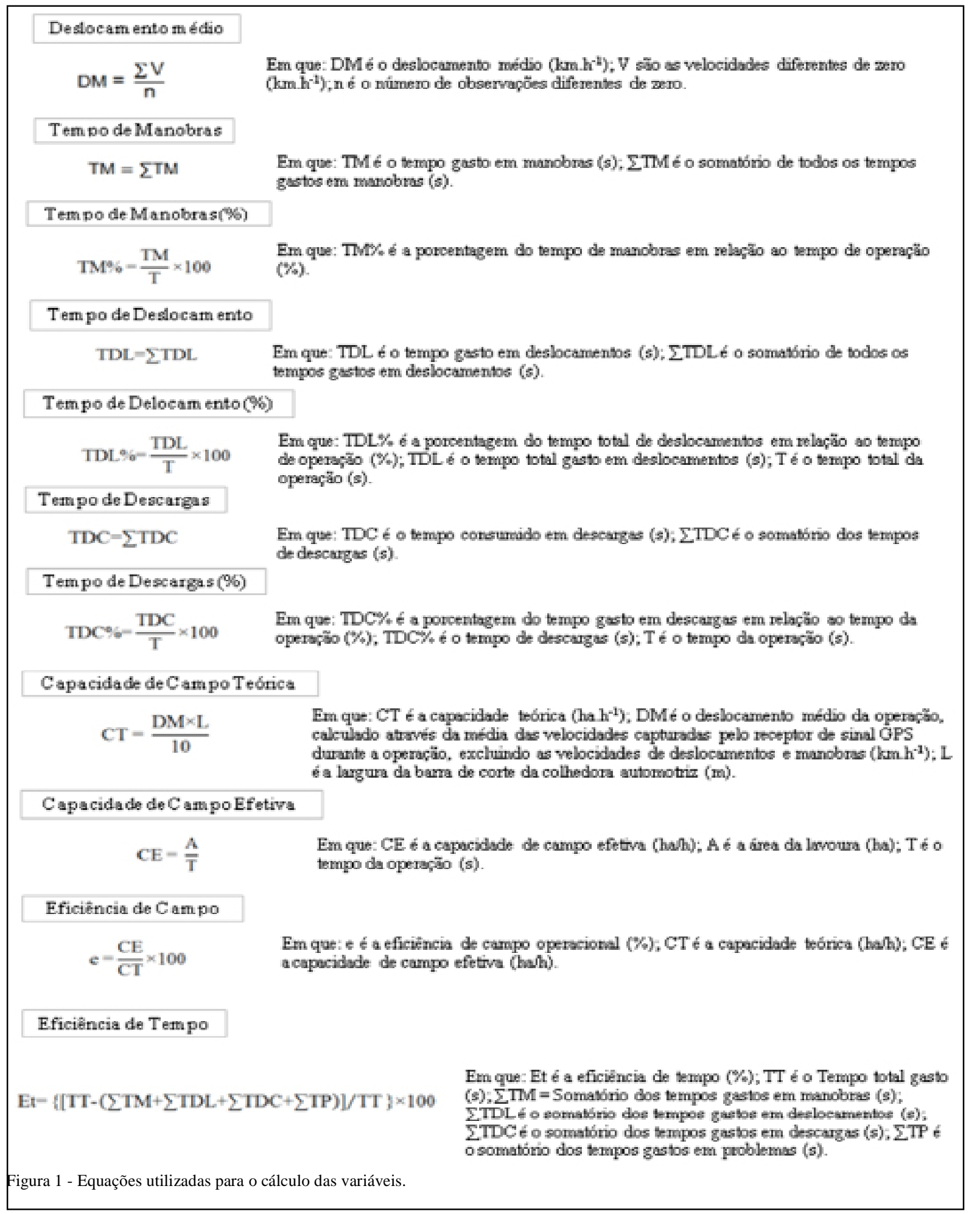

participaram com 38\% do tempo não aproveitável, conforme TAYLOR et al. (2002), contra os 2,67\% encontrados no presente trabalho; segundo, nas operações de soja e milho, as colhedoras se deslocavam até a borda da lavoura para realizar as descargas, o que contribuiu para o aumento do tempo 
Tabela 2 - Valores determinados de: eficièncias de campo (e\%), eficiência de tempo(Et\%), tempo de manobras (TM\%), tempo de deslocamento (TDL\%), tempo de descarga (TDC\%), tempo para a resolução de imprevistos (TP\%), tempos não aproveitáveis (TNA\%), relação comprimento/largura (F/W) e deslocamento médio (DM) para cada operação e coeficientes de correlação de Pearson entre $\mathrm{Et} \%$, e \%, TM\%, tempo de manobras sem os dados da propriedade E (TM\%E), TDL\%, TDC\%, tempo de descarga sem as operações da propriedade C que não tiveram descargas (TDC \%C) e DM\%.

\begin{tabular}{|c|c|c|c|c|c|c|c|c|c|c|}
\hline Sistematização & Propriedades & $\mathrm{Et} \%$ & $e^{\%} \%$ & TM $\%$ & TDL $\%$ & $\mathrm{TDC} \%$ & ТР\% & TNA\% $\%$ & $\mathrm{~F} / \mathrm{W}$ & $\begin{array}{c}\mathrm{DM} \\
\left(\mathrm{km} \mathrm{h}^{-1}\right)\end{array}$ \\
\hline \multirow{15}{*}{ SN } & $A$ & 78,8 & 77,6 & 8,4 & 1,5 & 7,4 & 4,0 & 21,2 & 3,3 & 1,6 \\
\hline & $A$ & 77,1 & 73,0 & 13,4 & 1,3 & 7,6 & 0,6 & 22,9 & 2,2 & 1,5 \\
\hline & $B$ & 76,5 & 60,2 & 7,2 & 2,6 & 13,7 & 0,0 & 23,5 & 3,5 & 1,4 \\
\hline & B & 80,9 & 72,7 & 7,4 & 0,8 & 11,0 & 0,0 & 19,1 & 1,4 & 1,3 \\
\hline & $\mathrm{C}$ & 77,9 & 60,8 & 15,1 & 1,7 & 5,2 & 0,0 & 22,1 & 2,2 & 2,4 \\
\hline & $\mathrm{C}$ & 73,5 & 58,7 & 25,0 & 1,4 & 0,0 & 0,0 & 26,5 & 1,0 & 2,2 \\
\hline & $\mathrm{C}$ & 74,2 & 60,3 & 23,1 & 2,7 & 0,0 & 0,0 & 25,8 & 2,1 & 2,5 \\
\hline & $\mathrm{C}$ & 62,4 & 56,2 & 19,3 & 3,8 & 14,5 & 0,0 & 37,6 & 4,6 & 2,5 \\
\hline & $\mathrm{D}$ & 75,0 & 72,0 & 17,4 & 0,2 & 7,4 & 0,0 & 25,0 & 1,1 & 2,1 \\
\hline & $\mathrm{D}$ & 75,9 & 73,4 & 14,8 & 1,2 & 8,1 & 0,0 & 24,1 & 1,5 & 2,0 \\
\hline & $\mathrm{D}$ & 57,4 & 55,8 & 12,2 & 1,1 & 29,3 & 0,0 & 42,6 & 1,5 & 2,0 \\
\hline & $\mathrm{E}$ & 87,6 & 70,1 & 2,3 & 0,8 & 9,4 & 0,0 & 12,4 & 6,2 & 1,9 \\
\hline & $\mathrm{E}$ & 77,7 & 56,5 & 2,4 & 3,2 & 16,7 & 0,0 & 22,3 & 24,1 & 2,4 \\
\hline & $\mathrm{E}$ & 72,7 & 50,8 & 3,5 & 5,3 & 18,5 & 0,0 & 27,3 & 19,7 & 2,3 \\
\hline & $\mathrm{E}$ & 67,7 & 61,4 & 4,4 & 0,5 & 24,0 & 3,5 & 32,3 & 3,3 & 2,0 \\
\hline \multirow{4}{*}{ SD } & A & 81,3 & 71,7 & 5,2 & 1,2 & 12,1 & 0,2 & 18,7 & & 1,9 \\
\hline & $\mathrm{D}$ & 81,6 & 66,9 & 15,3 & 1,4 & 1,7 & 0,0 & 18,4 & & 2,0 \\
\hline & $\mathrm{D}$ & 86,1 & 73,5 & 10,2 & 0,7 & 1,7 & 0,0 & 12,7 & & 1,8 \\
\hline & $\mathrm{F}$ & 73,8 & 67,0 & 4,2 & 2,1 & 16,3 & 0,0 & 26,3 & & 1,6 \\
\hline Médias & & 75,7 & 65,2 & 11,1 & 1,8 & 10,8 & 0,6 & 24,3 & 5,2 & 2,0 \\
\hline Eficiências & TM $\%$ & \multicolumn{2}{|c|}{$\mathrm{TM} \% \mathrm{E}$} & \multicolumn{2}{|c|}{ TDL $\%$} & $\mathrm{TDC} \%$ & & $\mathrm{TDC} \% \mathrm{C}$ & \multicolumn{2}{|c|}{$\mathrm{DM}\left(\mathrm{km} \cdot \mathrm{h}^{-1}\right)$} \\
\hline $\mathrm{Et} \%$ & $-0,3$ & \multicolumn{2}{|c|}{$-0,9$} & \multicolumn{2}{|c|}{$-0,3$} & $-0,6$ & & $-0,8$ & \multicolumn{2}{|c|}{$-0,3$} \\
\hline $\mathrm{e}^{\%} \%$ & $-0,1$ & \multicolumn{2}{|c|}{$-0,5$} & \multicolumn{2}{|c|}{$-0,7$} & $-0,4$ & & $-0,6$ & \multicolumn{2}{|r|}{$-0,6$} \\
\hline
\end{tabular}

perdido; terceiro, maior deslocamento médio, média de $4,91 \mathrm{~km} \mathrm{~h}^{-1}$, contra $1,97 \mathrm{~km} \mathrm{~h}^{-1}$ deste trabalho.

Eficiência de campo (e\%)

A eficiência de campo média encontrada foi de $65,2 \%$ e variou de $50,8 \%$ a $77,6 \%$ (Tabela 2). O menor valor de eficiência está relacionado com o tempo total de descargas e o tempo total de deslocamentos, pois essas variáveis ficaram acima da média verificada pela amostragem. $\mathrm{O}$ maior valor é resultado dos dois fatores que mais influenciaram o tempo não aproveitável, TM\% e TDC\%, pois eles ficaram abaixo de suas médias (Tabela 2).

O valor médio encontrado de $65,2 \%$ está bem próximo ao valor encontrado por KALSIRISILP (1993), 66\%, porém, em relação aos valores médios encotrados por TAYLOR et al. (2002), 54\%, e GRISSO $(2002,2004), 53,5 \%$ e $59 \%$, a e $\%$ média do presente trabalho ficou acima da obtida por esses dois autores. No entanto, cabe ressaltar que estes dois últimos autores avaliaram operações de colheita de milho e soja, nas quais as velocidades de deslocamento são maiores.

Estabelecendo um comparativo entre os valores de eficiência de campo citados pela norma ASAE D497.6 (2009) e os valores encontrados no presente trabalho, a diferença entre o maior e menor valor de variação obteve valores inferiores aos normatizados pela associação, porém, a média situou-se dentro dos limites trazidos pelo órgão, o que também ocorreu para KALSIRISILP (1993) e não ocorreu para TAYLOR et al. (2002) e GRISSO (2002, 2004) (Tabela 3).

O deslocamento médio da colhedora e o seu tempo de deslocamento mostraram as maiores correlações negativas com a eficiência de campo (Tabela 2), confirmando que o aumento dos tempos de deslocamento e da velocidade de deslocamento reduzem 
Tabela 3 - Comparativo entre os valores de eficiência de campo (e\%) encontrados, os citados por KALSIRISILP (1993), TAYLOR et al. (2002) e GRISSO et al. (2002,2004), e os estabelecidos pela ASAE D497.6 JUN2009.

\begin{tabular}{|c|c|c|c|c|}
\hline & \multicolumn{4}{|c|}{--oriciencia de Campo (\%) } \\
\hline & Variação & Típica & Variação & Típica \\
\hline ASAE D497.6 JUN2009 & $65-80$ & 70 & $3,0-6,5$ & 5 \\
\hline Obtida no presente trabalho & $51,0-77,5$ & 65 & $1,3-2,4$ & 2 \\
\hline KAISIRISILP (1993) & $28,0-92,0$ & 66 & ------ & --.--.- \\
\hline TAYLOR et al. (2002) & $29,0-75,0$ & 54 & $3,0-5,8$ & 4,91 \\
\hline GRISSO et al. (2004) & $53,2-66,9$ & 59 & ------ & ------- \\
\hline GRISSO et al. (2002) & $35,6-69,9$ & 53,5 & ------.- & -----.-- \\
\hline
\end{tabular}

a eficiência de campo. O tempo total de manobras, o tempo total de descargas e o tempo total de problemas apresentaram uma baixa correlação negativa. Porém, quando calculamos o coeficiente de correlação para o tempo total de manobras sem os tempos de manobras da propriedade $\mathrm{E}(\mathrm{TM} \% \mathrm{E})$, estas lavouras mostraram números que se distanciaram dos encontrados como média. Observando o coeficiente de correlação para tempo de descargas sem as duas lavouras da propriedade $\mathrm{C}$ (TDC\% C), que não tiveram estes tempos, e o coeficiente para o tempo de problemas, só para as operações que enfrentaram algum problema (TP\%P), obtemos um considerável aumento (Tabela 2), mostrando que essas variáveis também estão bastante relacionadas com a eficiência de campo.

Através do cálculo da eficiência de campo sem os tempos de descargas e para resolução de imprevistos (ec\%), pôde-se verificar que estes diminuíram em aproximadamente $11,8 \%$ a eficiência de campo, ou, a eliminação desses tempos pôde aumentar aproximadamente $13,4 \%$ na eficiência encontrada no campo neste trabalho (Figura 2).

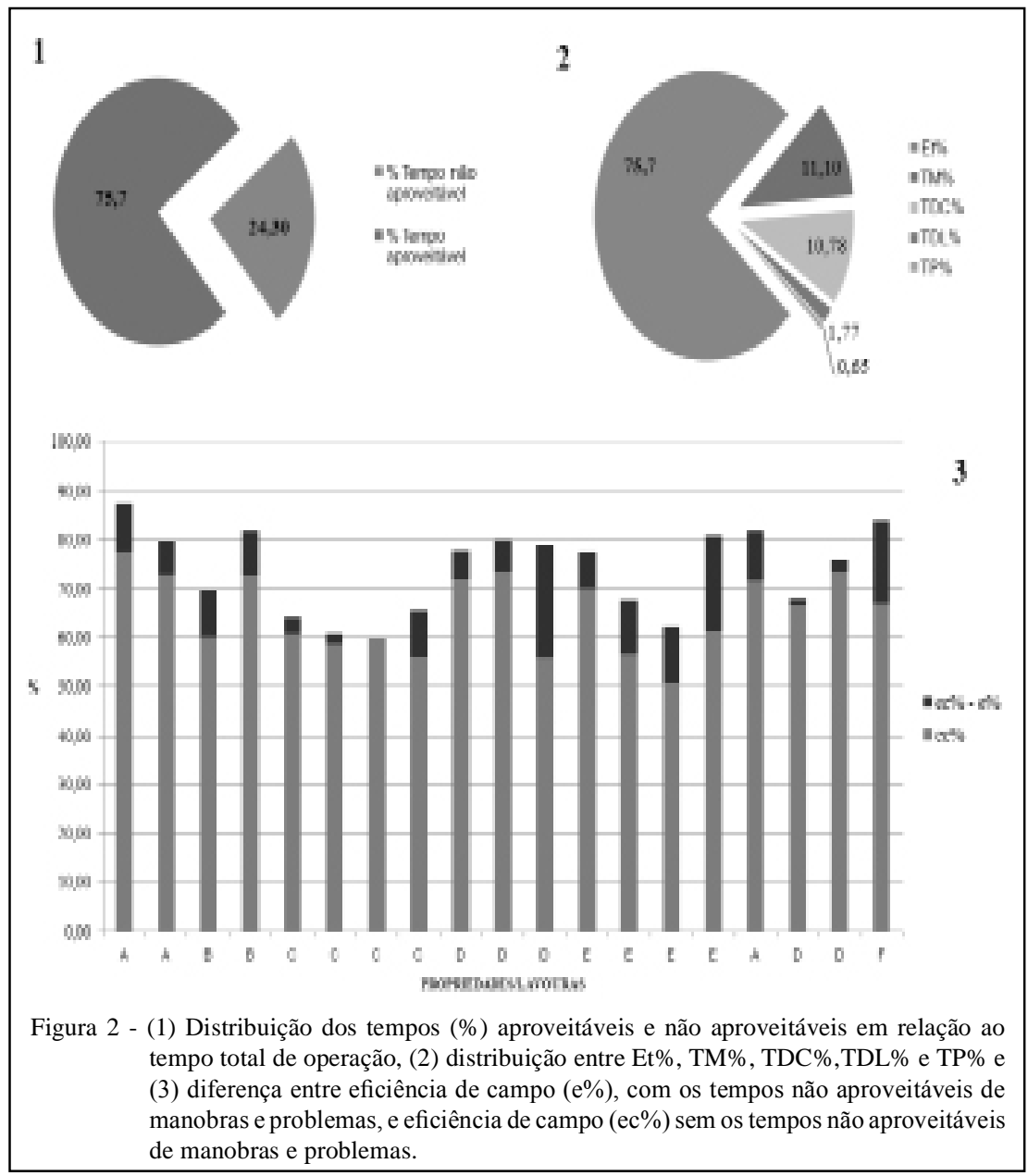

Ciência Rural, v.43, n.3, mar, 2013. 


\section{CONCLUSÃO}

Para as variáveis e\%; Et\%; TM\%; TDL\%; TDC\%, não houve diferença significativa entre as duas modalidades de sistematização. Os valores médios encontrados para as eficiências de campo e de tempo foram de $65,2 \%$ e $75,7 \%$, respectivamente. Para eficiência de campo, tanto os valores da variação como a média foram inferiores aos da ASAE D497.6 (2009), porém a média situou-se dentro, entre os limites citados.

As manobras e descargas consumiram em média 11,1 e $10,8 \%$ do tempo total nas operações analisadas, respectivamente. Eliminando-se os tempos de descargas e de imprevistos, pode-se aumentar aproximadamente $13,4 \%$ a eficiência de campo. As variáveis com maior correlação com a redução das eficiências foram tempo de deslocamento e velocidade de deslocamento, para eficiência de campo, e tempo de descarga, para eficiência de tempo.

\section{REFERÊNCIAS}

ASAE (AMERICAN SOCIETY OF AGRICULTURAL ENGINEERS). ASAE EP 496.2 FEB03: Agricultural machinery management data. In: ___ ASAE Standards 2003: standards engineering practices data. St. Joseph, 2003. p.366-372.

ASAE (AMERICAN SOCIETY OF AGRICULTURAL ENGINEERS). ASAE EP 497.6 JUN09: Agricultural machinery management data. In: ___ ASAE Standards 2009: standards engineering practices data. St. Joseph, 2009. p.350-357.

ERENO, L.H.Z. Estudo comparativo entre a utilização real e a determinada pelo planejamento da mecanização agrícola em empresas rurais de soja e arroz. 2008. 103f. Dissertação
(Mestrado em Engenharia Agrícola) - Universidade Federal de Santa Maria, Santa Maria, RS.

FERREIRA, D.F. SISVAR: um programa para análises e ensino de estatística. Revista Symposium, v.6, n.2, p.36-41, 2008.

HUNT, D. Farm power and machinery management/Donnell Hunt. Ames: Iowa state, 2001. 368p.

IRGA (INSTITUTO RIO GRANDENSE DO ARROZ). Custo de produção de arroz irrigado no RS: Safra 09/10 safra 2009/2010, 2010. Disponível em: <http://www.irga.rs.gov.br/uploads/ anexos/1293728428Custos_de_Producao.pdf $>$. Acesso em: 16 dez. 2010.

FAO. A guide to preparing an agricultural mechanization strategy. Rome, 1997. 38p. CD-Rom.

Analysis of traffic patterns and yield monitor data for field efficiency determination. Applied Engineering in Agriculture, v.18, n.2, p.171-178, 2002.

GRISSO, R.D. et al. Field efficiency determination using traffic pattern indices. Applied Engineering in Agriculture, v.20, n.5, p.563-572, 2004.

PERIN, G.F. Determinação da capacidade e eficiência operacional utilizando técnicas de agricultura de precisão. 2008. 114f. Dissertação (Mestrado em Engenharia Agrícola) Universidade Federal de Santa Maria, Santa Maria, RS.

TAYLOR, R.K. et al. Using GPS technology to evaluate corn planter performance. In: ANNUAL INTERNATIONAL MEETING SPONSORED BY ASAE, 2001, Sacramento, California. Proceedings... California: ASAE, 2001. p.01-11.

TAYLOR, R.K. et al. Extracting machinery management information from GPS data. St. Joseph: ASAE, 2002. 9p. (ASAE Paper, 021008).

WITNEY, B. Choosing and using farm machines. Essex: Longman Scientific and Technical, 1988. 412p. 